\begin{tabular}{|c|l|}
\hline Title & Production of slow-released nitrogen fertilizer from urine \\
\hline Author(s) & Ito, Ryusei; Takahashi, Eri; Funamizu, Naoyuki \\
\hline Citation & $\begin{array}{l}\text { Environmental technology, 34(20), 2809-2815 } \\
\text { https://doi.org/10.1080/09593330.2013.790069 }\end{array}$ \\
\hline Issue Date & 2013-10-01 \\
\hline Doc URL & http://hdl.handle.net/2115/57595 \\
\hline Rights & $\begin{array}{l}\text { Thisis an Accepted Manuscript of an article published by Taylor \& Francisin Environmental Technology on 2014, } \\
\text { available online: http:/www.tandfonline.com/10.1080/09593330.2013.790069 }\end{array}$ \\
\hline Type & article (author version) \\
\hline File Information & production of slow release_rev3.pdf \\
\hline
\end{tabular}

Instructions for use 


\section{PRODUCTION OF SLOW-RELEASED NITROGEN FERTILIZER FROM URINE}

\section{Ryusei Ito}

Water, Decontamination, Ecosystem and Health Laboratory, International Institute for Water and Environmental Engineering (2iE), 01, BP 594, Ouagadougou, 01, Burkina Faso,

Laboratory on Engineering for Sustainable Sanitation, Faculty of Engineering, Hokkaido University, Kita 13 Nishi 8, Kita-ku, Sapporo, Hokkaido, 060-8628, Japan, e-mail: ryuusei@eng.hokudai.ac.jp

Eri Takahashi

Laboratory on Engineering for Sustainable Sanitation, Graduate School of Engineering, Hokkaido University, Kita 13 Nishi 8, Kita-ku, Sapporo, Hokkaido, 060-8628, Japan

Naoyuki Funamizu

Laboratory on Engineering for Sustainable Sanitation, Graduate School of Engineering, Hokkaido University, Kita 13 Nishi 8, Kita-ku, Sapporo, Hokkaido, 060-8628, Japan 


\title{
PRODUCTION OF SLOW-RELEASED NITROGEN FERTILIZER FROM URINE
}

\author{
Human excreta, especially urine is rich in nitrogen to be able to utilize into the \\ agricultural purposes, while the slow-release fertilizer allows effective utilization \\ of nutrients in agricultural production. The direct formation of slow-release \\ fertilizer - methylene urea - from urine was being proposed in this study. The \\ experiments were tried to prove formation of methylene urea from human urine, \\ and to investigate the effect of the $\mathrm{pH}$ and salt concentration on the reaction rate. \\ The synthetic urine and real urine were used for urea source of the reaction. As a \\ result, the precipitates were prepared from synthetic urine, while the small \\ molecule fractions generated then they growth to precipitate. The NMR, IR, \\ element analyses showed the precipitation in synthetic urine must be same \\ compound from urea solution which is methylene urea. The reaction rate was \\ high at low $\mathrm{pH}$ value. The reaction rate in buffer solution was lower than \\ synthetic urine at same $\mathrm{pH}$, because some salts may work as catalyst. The urea \\ concentration reduction rate in real urine showed same trend with synthetic urine \\ at same $\mathrm{pH}$, while the precipitation was quite similar to methylene urea.
}

Keywords: methylene urea, nitrogen recovery, human urine, $\mathrm{pH}$, salt concentration

Subject classification codes: include these here if the journal requires them

\section{Introduction}

Nitrogen fertilizers, such as ammonia, urine nitrate salts are the great elements for agriculture. They are able to increase the productivity of fruits or grains on the poor lands. Currently, $100 \mathrm{M}$ ton-N of nitrogen fertilizers are produced and consumed in the world par year [1] for agricultural purposes while their market is still developing to satisfy the growing food demands especially in developing countries. Here, the production of ammonia, which is main resource of other nitrogen fertilizers, requires 34.5GJ/ton-N of energy [2] by steam reforming method. This fact shows the energy 
consumption of ammonia in the world corresponds to a few percent of annual net electricity consumptions in the world.

The conventional nitrogen fertilizers are very big solubility into water, resulting in low efficiency by flushing out with rain. These phenomena cause the redundant consumption and nitrification of surface water. So, the controlled release fertilizers are developing to avoid this problem. Trenkel [3] reports the efficiency of nitrogen fertilizer was only $25 \%$ for tomato and $22 \%$ for rice. However, the efficiency of controlled release fertilizer was $66 \%$ for tomato and $79 \%$ for rice. To realize the function, there are two types, coated fertilizer and low solubility materials [4-6]. The coated one is the conventional fertilizers with coated layer. The release rate is controlled by physical and chemical properties of the coating layer, permeability of water, size of the particles etc [7-14], however the coating layer should remain in the soil. The latter is special materials, such as methylene urea, isobutylidene-diurea, cyclodiurea, guanyl urea and oxamide urea, which have low the solubility and low degradation rate to control the release rate of nitrogen nutritive into the soil system [15]. The industrial production of methylene urea is well known as following step reactions of urea and formaldehyde;

1. Addition reaction under acidic condition<smiles>NC(N)=O</smiles><smiles>O=CC=O</smiles><smiles>CCCCCCCCCC(N)=O</smiles>

(1)

2. Dehydrate condensation and polymerization 
<smiles>NC(=O)NCO</smiles><smiles>CCCCCCCCCCCCCCC(N)=O</smiles><smiles>CCCCCC(C)(C)NCNC(=O)CC</smiles>

Both reactions are electrophilic addition reaction which catalyzed by proton of acids resulting in high reaction rate at low $\mathrm{pH}$ value. In usual industry, heating process is applied for accelerating the reaction rates and increasing the degree of the polymerization, however the reaction advances under room temperature. The solubility and biodegradation rate of the methylene urea are controlled by the degree of polymerization.

Focusing on human excreta, $850 \mathrm{~g}$ of nitrogen is evacuated from a person per year [16], while human being on the earth excretes about $6 \mathrm{M}$ ton of nitrogen per year. The human urine contains $86 \%$ of nitrogen in the excreta [17]. Most of the nitrogen exists as urea formation which easily decomposes into ammonium formation by biological activity and hydrolysis reaction resulting from contamination of faces [18]. So, recovery of nitrogen from urine has potential to reduce energy consumption for producing nitrogen fertilizer and the production of controlled release fertilizer has larger impact to energy problem by increasing nitrogen utilization efficiency. 
We are proposing the production of controlled release fertilizer by a direct formation process of methylene urea from human urine. The real urine contains many inorganic salt and unknown organic matters, which are concerned to causes sub-reaction of undesired compounds. Considering actual reaction system, controlling $\mathrm{pH}$ is one of the easiest processes and recovery ratio should be evaluated for find effective reaction conditions. The aims of this paper are to prove formation of methylene urea from synthetic urine and real human urine, and to investigate the effect of the $\mathrm{pH}$ and salt concentration on the reaction rate and recovery of urea form nitrogen. The structure of the production was analyzed by C13-NMR, IR spectrum and element analysis.

\section{Methods}

\section{Reaction in synthetic solution}

The composition of the synthetic urine is summarized in Table 1 [19]. Agents of JIS special grade provided by Wako Pure Chemical Industries, Ltd. were utilized for preparation of synthetic urine. The $\mathrm{pH}$ values of the solutions were controlled by addition of $1 \mathrm{~mol} / \mathrm{L}$ sulfuric acid (JIS special grade, Wako Pure Chemical Industries, Ltd.) with monitoring $\mathrm{pH}$ meter before starting the reactions. $600 \mathrm{ml}$ of synthetic urine was taken in beakers, then was kept at $20{ }^{\circ} \mathrm{C}$ in a water bath. $30 \mathrm{ml}$ of $30 \%$ formaldehyde solution (JIS special grade, Wako Pure Chemical Industries, Ltd.) was added to the beakers to start the reactions, while the solutions were mixed by magnetic stirrer during the reaction. After the reaction duration, $1 \mathrm{~mol} / \mathrm{L}$ sodium hydroxide solution (JIS special grade, Wako Pure Chemical Industries, Ltd.) was added to put its $\mathrm{pH}$ value at 7 for stopping the reaction. The liquid and precipitates were filtrated by $0.45 \mu \mathrm{m}$ membrane filter then weight of the residue on the filter was measured by 
electric balance. The filtrates were dialyzed with UF membrane tubes which had cut off of $100 \mathrm{kDa}, 10 \mathrm{kDa}$ and $1 \mathrm{kDa}$ (Spectra/Por Biotech Cellulose Ester (CE) Dialysis Membranes). The $10 \mathrm{ml}$ of liquid sample was put into the tubes then was sealed. The tubes were put into the ion exchanged water in the refrigerator for 2 days and the water was changed every 6-12 hours. The nitrogen concentrations in the tubes were measured by Kjeldahl method. The precipitates on the filter were well washed with ion exchanged water. The molecule structure of the precipitation was analyzed by C13-NMR (ECX400, JEOL), solid IR spectrum and elemental analyzer (CHN corderMT-6, YANACO). For the reference, the $50 \mathrm{~g} / \mathrm{L}$ of urea solution was prepared and add $1 \mathrm{~mol} / \mathrm{L}$ sulfuric acid to set the $\mathrm{pH}$ at $2.200 \mathrm{ml}$ of urea solution and $10 \mathrm{ml}$ of $30 \%$ formaldehyde solution were mixed by magnetic stirrer at $20{ }^{\circ} \mathrm{C}$ for 240 hours. The precipitates in the solution were recovered by filtration with $0.45 \mu \mathrm{m}$ membrane filter, well washed by ion exchanged water, and then their molecular structure was analyzed by same methods of the precipitates from the synthetic urine solutions.

\section{Effect of $p H$ and salt concentration on the reaction rate}

The synthetic urine solutions with $\mathrm{pH}$ 1, 2, 3, 4 and 5 and without $\mathrm{pH}$ control were prepared by following the protocol above. $200 \mathrm{ml}$ of synthetic urine solutions were taken in beakers kept at $20{ }^{\circ} \mathrm{C}$ in a water bath. $10 \mathrm{ml}$ of $30 \%$ formaldehyde solution was added to the beakers and mixed be magnetic stirrers during the reaction. Some part of liquid was sampled periodically. The sample solutions were filtrated with $0.45 \mu \mathrm{m}$ membrane filter. The urea concentrations in the filtrates were measured by the diacetyl monoxime test [20]. The molecular distribution of the synthetic solution with $\mathrm{pH} 5$ follows same procedure mentioned above. 


\section{Application to real urine}

The real urine was taken from 4 volunteers then stored at $2{ }^{\circ} \mathrm{C}$ refrigerator, and was applied to experiment in 1 day. The reaction follows the protocol of the experiment for different $\mathrm{pH}$ values. $200 \mathrm{ml}$ of urine was taken in a beaker, while the $\mathrm{pH}$ is adjusted at 2 with addition of the $1 \mathrm{~mol} / \mathrm{L}$ sulfuric acid. The urea concentration in the liquid phase and molecular structure of the precipitates were analyzed.

\section{Results and discussion}

\section{Production of methylene urea from synthetic urine}

The methylene urea formation from urea solution and formaldehyde is well known to be used for industrial production. Urine is rich in urea with high concentration of salts and organic matters, which probably affect the reaction.

Figure 1 shows the time course of the molecular distribution of derivatives of urea and other compounds that contains nitrogen element at $\mathrm{pH} 2.1600 \mathrm{mmol}$ of urea and 100 mmol of creatinine and ammonium chloride were found in the synthetic urine at initial. During the experiments in this paper, the concentrations of creatinine and ammonium chloride were assumed not to change, because the concentration was enough lower than urea concentration. The urea concentration decreased with elapse of the time to form the components of larger molecular size and precipitates, but total amount of nitrogen element did not change. The components with the range of $10 \mathrm{k}-100 \mathrm{kDa}$ were the largest at 1 hour then decreased. These phenomena show the polymerization process of urea derivatives. Therefore, it is gathered that the reaction follows the process of methylene urea production. Then, the precipitates from synthetic urine was analyzed by the means of C13-NMR, IR spectrometry and element analysis. Figure 2 shows the NMR chart of the precipitates. There are two peaks which represent the methylene group $\left(-\mathrm{CH}_{2}-50 \mathrm{ppm}\right)$ and the ketone group $(-\mathrm{C}=\mathrm{O}-160 \mathrm{ppm})$. This chart is similar to 
the precipitates from urea solution as illustrated in Figure 3. As mentioned above, the reaction of formaldehyde in urea solution at acidic condition prepares precipitates of methylene urea. So, this compound from synthetic urine should be near to methylene urea. The IR spectrum of the precipitates of synthetic urine is shown in Figure 4. Three groups of peaks, such as N-H bound $\left(3500 \mathrm{~cm}^{-1}\right), \mathrm{C}=\mathrm{O}$ bound $\left(1800 \mathrm{~cm}^{-1}\right)$ and $\mathrm{C}-\mathrm{N}$ bound $\left(>1500 \mathrm{~cm}^{-1}\right)$ are found in it. These peak groups were also found in the IR spectrum of methylene urea from urea solution as illustrated in Figure 5. From these data, we can assume that the production is the derivatives of methylene urea described by equation (1). The element analysis of the precipitates from synthetic urine and urea solution respectively showed the weight ratio of each element as C: $28.52 \%, \mathrm{H}: 5.57 \%$, N: $35.33 \%$ and C: $29.78 \%, \mathrm{H}: 5.59 \%, \mathrm{~N}: 36.82 \%$. The rest should be Oxygen or other elements. These values are almost equal, so that it is seems that the same substances are produced from synthetic urine and urea solution.

\section{Effect of $\mathrm{pH}$ and salt concentration on the reaction rate of methylene urea}

Figure 6 shows the time course of the urea concentration in the liquid phase with different $\mathrm{pH}$ values. The urea concentration decreased with elapse of time at all $\mathrm{pH}$ values, while the rate was high at low $\mathrm{pH}$. This is because, the electrophilic addition reaction which is catalyzed by proton occurs on the reaction of urea and formaldehyde resulting in high reaction rate at high proton concentration. The production and reaction rates of the component with the range of $10 \mathrm{k}-100 \mathrm{kDa}$ at $\mathrm{pH} 5$ are lower than them at $\mathrm{pH} 2$ as illustrated in Figure 7. This also shows the effect of the proton concentration. The urea concentration of $\mathrm{pH} 5$ condition at the steady state was higher than $\mathrm{pH} 2$. Some sub-reaction to stop the main reaction might occur, but about this point, more analysis is required. 
To investigate the effect of salt concentration, the time courses of the urea concentration in the urea buffer solution at $\mathrm{pH} 2$ and $\mathrm{pH} 5$ are presented in Figure 8. In urea solution, the reaction rate was fast at low $\mathrm{pH}$ value, and lower than in the synthetic urine at same $\mathrm{pH}$ values. The buffer solution has low salt concentration, so that the salts may have catalytic activity to accelerate the reaction.

\section{Application to real urine}

Figure 9 represents the reaction rate in the real urine which $\mathrm{pH}$ was adjusted at 2 . There was slight difference between the reaction rate and urea concentration in liquid phase in the real and in synthetic urine, while the precipitates also obtained. The precipitation from real urine was analyzed by the means of C13-NMR, IR spectrum and element analysis to check its quality as illustrated in Figures 10 and 11. The NMR chart has 2 big peaks and 3 small peaks around $60 \mathrm{ppm}$. The big peaks seems to be same function groups (-CH2- 50 ppm and -CO- 160 ppm) in Figure 2 (precipitate from synthetic urine) and 3 (precipitates from urea). The small peaks may suggest existence of unknown functional groups or unknown derivative of - $\mathrm{CH} 2$ - group. In the IR spectrum of precipitates from real urine, three bound groups as $\mathrm{N}-\mathrm{H}$ bound, $\mathrm{C}=\mathrm{O}$ bound and $\mathrm{C}-\mathrm{N}$ bound were also found and this IR analysis did not show the difference between the real urine case and the synthetic urine, urea cases (Figures 4 and 5). The element analysis showed the result of the contents, C: $29.61 \%, \mathrm{H}: 5.85 \%$ and $\mathrm{N}: 30.35 \%$ and this means that the nitrogen content was lower than other precipitates. Even the lower nitrogen content of precipitate from real urine, the nitrogen content of the precipitates is sufficient level for nitrogen fertilizer [21]. From the above results, it might be concluded that the main constituents of the precipitation from real urine was methylene urea and the precipitates may contain trace unknown function groups which is deficiency of 
nitrogen. It requires to more analysis for other elements or functional groups in the precipitation.

\section{Conclusions}

The slow-release fertilizer of methylene urea was tried to prepare from urine solutions. As a result, the precipitates were prepared from synthetic urine, while the small molecule fractions generated then they growth to precipitate. The NMR, IR analyses showed the precipitation in synthetic urine must be same compound from urea solution which is methylene urea. Element analysis showed the weight ratios of the compounds from synthetic and buffer solution, which were respectively $\mathrm{C}: 28.52 \%, \mathrm{H}$ : 5.57\%, N: $35.33 \%$ and C: $29.78 \%, \mathrm{H}: 5.59 \%, \mathrm{~N}: 36.82 \%$. The reaction rate was high at low $\mathrm{pH}$ value. This is because the reaction was electrophilic addition reaction as described by Eq. (1) which catalyzed by proton of acids. The reaction rate in buffer solution was lower than synthetic urine at same $\mathrm{pH}$, because some salts may work as catalyst. The urea concentration reduction rate in real urine was same with synthetic urine at same $\mathrm{pH}$. The NMR, IR analysis showed the precipitation should be quite similar compound to methylene urea. The weight composition of the precipitates was C: $29.61 \%, \mathrm{H}: 5.85 \%$ and $\mathrm{N}: 30.35 \%$ by the element analysis.

\section{References}

[1] FAO, FAOSTAT, (2009). Available at http://faostat.fao.org/.

[2] G. Kongshaug, Energy Consumption and Greenhouse Gas Emissions in Fertilizer Production, in IFA Technical Conference, (1998).

[3] M. E. Trenkel, Use Efficiency Controlled-Release and Stabilized Fertilizers in Agriculture. (1997). 
[4] Toray Research Center, Jyoho Gijutu to Yoto Tenkai. (1997), pp. 1 - 8.

[5] R. W. Baker and H. K. Lonsdale, Controlled Release of Biologically Active Agents. Plenum, New York, (1973), pp. 15 - 71.

[6] C. Berkland, M. King, A. Cox, K. Kim, and D. W. Pack, Precise control of PLG microsphere size provides enhanced control of drug release rate, Journal of Controlled Release 82 (2002), pp. 137 - 147.

[7] R. Ito, B. Golman, and K. Shinohara, Controlled Release of Core Particle Coated with Soluble Particles in Impermeable Layer, Journal of Chemical Engineering of Japan 35 (2002), pp. 40-45.

[8] R. Ito, B. Golman, and K. Shinohara, Controlled release with coating layer of permeable particles, Journal of Controlled Release 92 (2003), pp. 361-368.

[9] R. Ito, B. Golman, and K. Shinohara, Effect of the Porous Structure of a Coating Layer on the Release Rate of Core Particle, Journal of Chemical Engineering of Japan 36 (2003), pp. 676-682.

[10] R. Ito, B. Golman, and K. Shinohara, Formation of a sigmoidal release pattern of core particles coated with layers of soluble and permeable particles, Advanced Powder Technology 15 (2004), pp. 377-390.

[11] R. Ito, B. Golman, and K. Shinohara, Multiple-Layer Coating of Solids with Impermeable Film Dispersing Permeable Particles for Controlled Release, Journal of Chemical Engineering of Japan 37 (2004), pp. 496-502.

[12] R. Ito and K. Shinohara, Design of multi-layer coated particles with sigmoidal release pattern, Chemical Engineering Science 60 (2005), pp. 5415-5424.

[13] U. Shavit and A. S. M. Reiss, Wetting mechanisms of gelbased controlled-release fertilizers, Journal of Controlled Release 88 (2003), pp. $71-83$.

[14] N. Shimono, T. Takatori, M. Ueda, M. Mori, Y. Higashi, and Y. Nakamura, Chitosan dispersed system for colon-specific drug delivery, International Journal of Pharmaceutics 245 (2002), pp. 45 - 54.

[15] S. Shoji, Meister: Controlled Release Fertilizer: Properties and Utilization. Konno Printing, Sendai, (1999), pp. $16-20$.

[16] M. Almeida, D. Butler, and E. Friedler, At-source domestic wastewater quality, Urban Water 1 (1999), pp. 49-55.

[17] A. F. Malisie, M. Prihandrijanti, and R. Otterpohl, The potential of nutrient reuse from a source-separated domestic wastewater system in Indonesia--case study: ecological sanitation pilot plant in Surabaya., Water science and technology : a journal of the International Association on Water Pollution Research 56 (2007), pp. 141-148. 
[18] S. Hotta and N. Funamizu, Evolution of ammonification potential in storage process of urine with fecal contamination., Bioresource technology 99 (2008), pp. $13-17$.

[19] J. A. Wilsenach, C. A. H. Schuurbiers, and M. C. M. van Loosdrecht, Phosphate and potassium recovery from source separated urine through struvite precipitation., Water research 41 (2007), pp. 458-66.

[20] WHO, Standard Operating Procedures for CLINICAL CHEMISTRY - Diacetyl Monoxime Method. Available at http://www.searo.who.int/en/Section10/Section17/Section53/Section481_1754.ht m.

[21] Ministry of Agriculture Forestry and Fisheries, Fertilizers Regulation Act. (1950). 


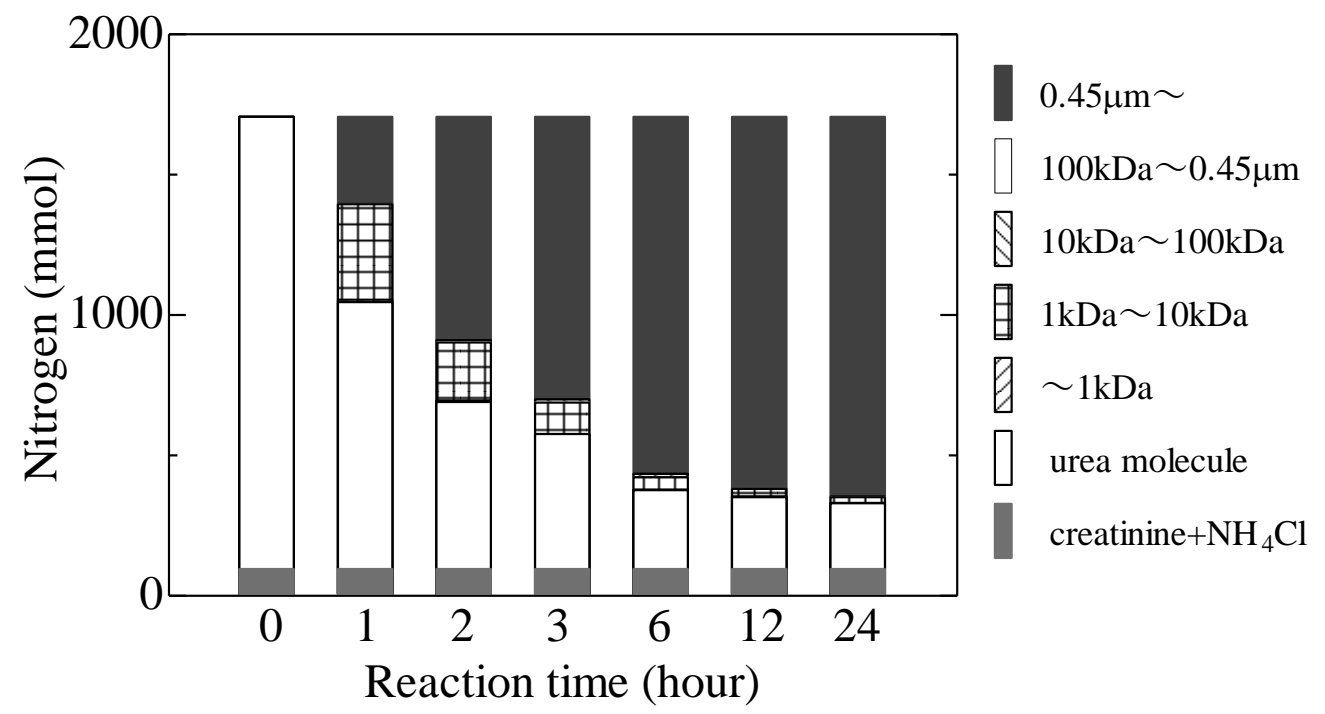

Figure 1 Molecular distribution of urea derivatives at $\mathrm{pH} 2$ 
13C CP/MAS 2

$\frac{x}{2}$
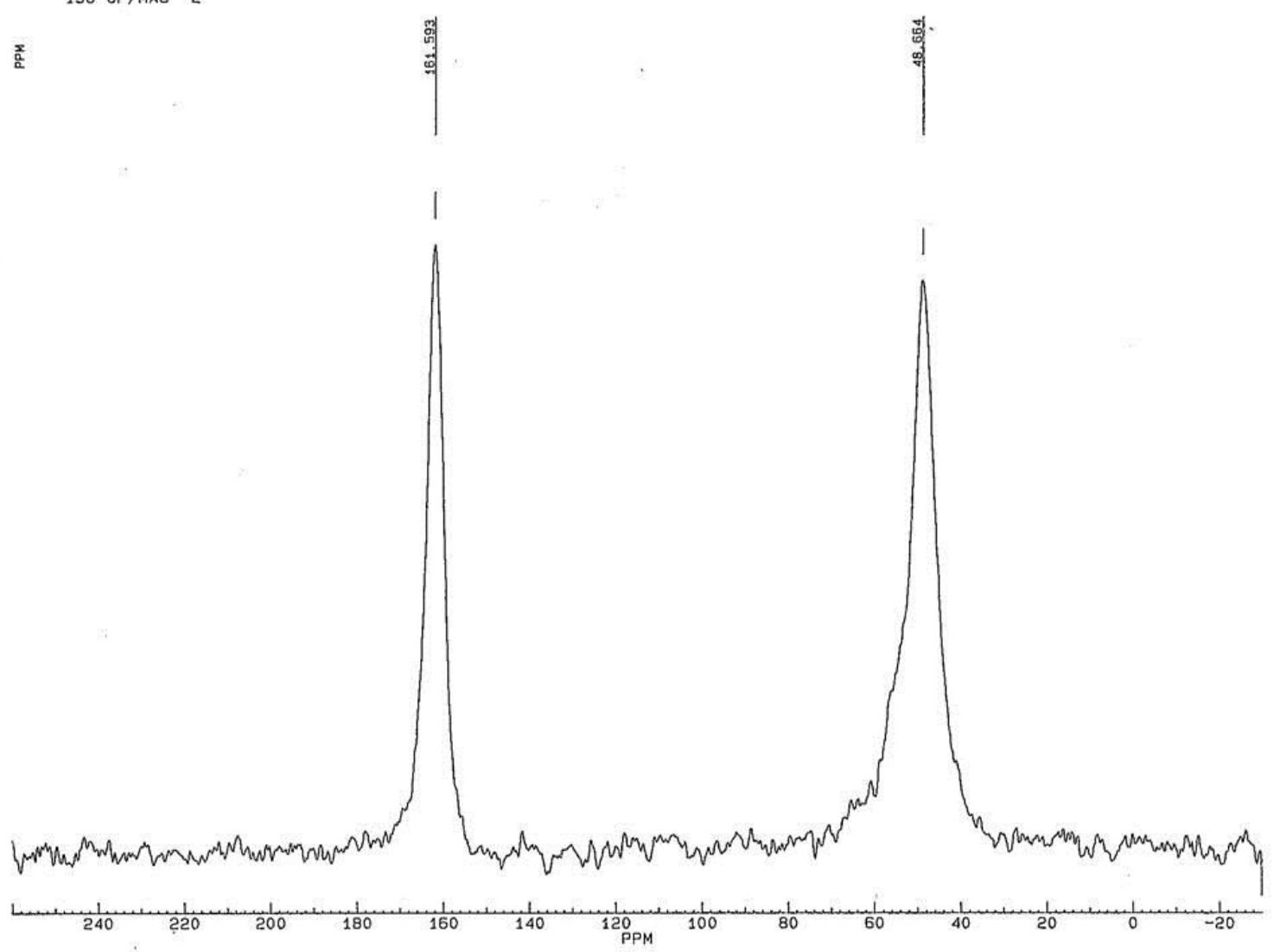

Figure 2 NMR spectrum of precipitates from synthetic urine 
13C CP/MAS

ż
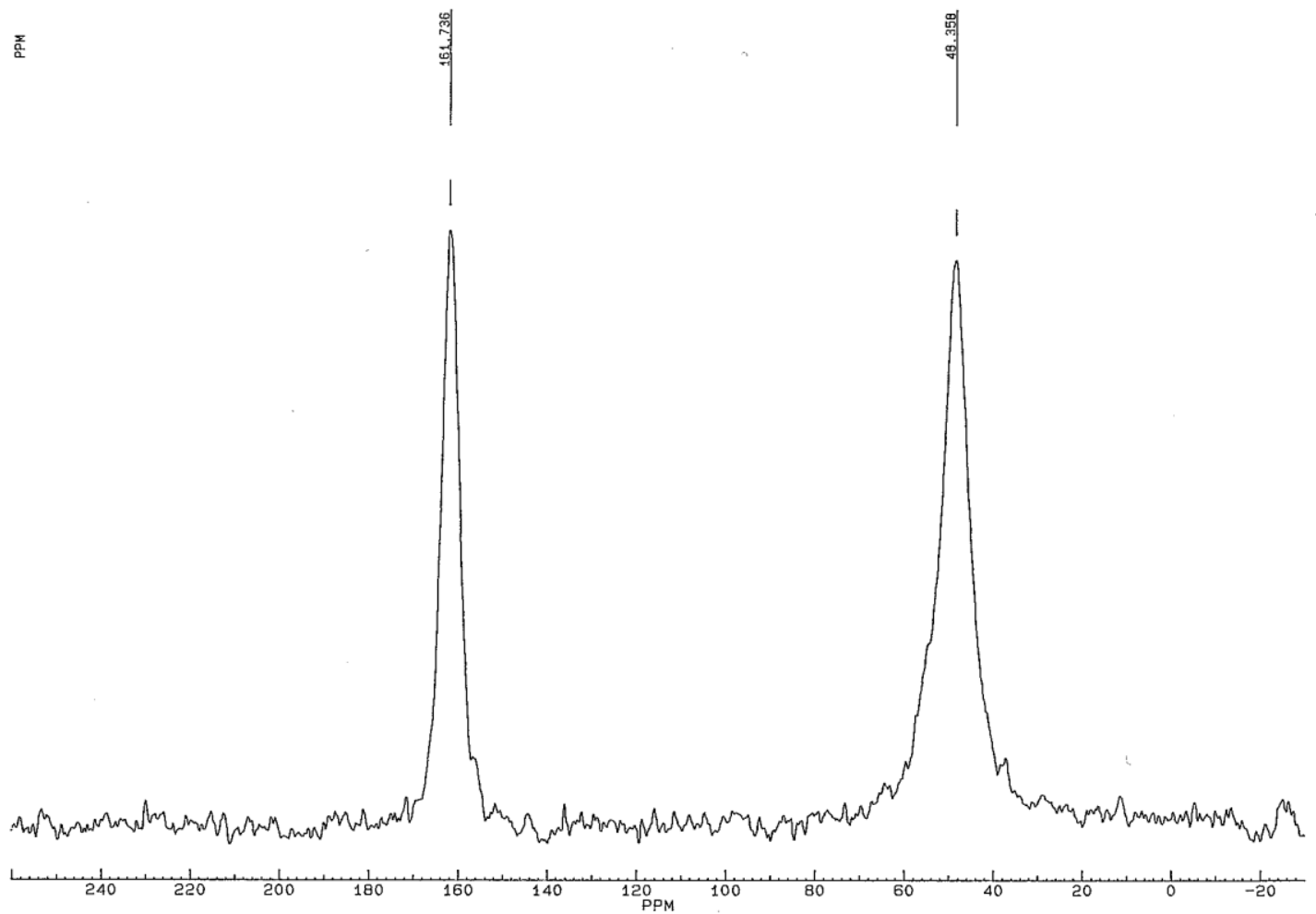

Figure 3 NMR spectrum of precipitates from urea solution 


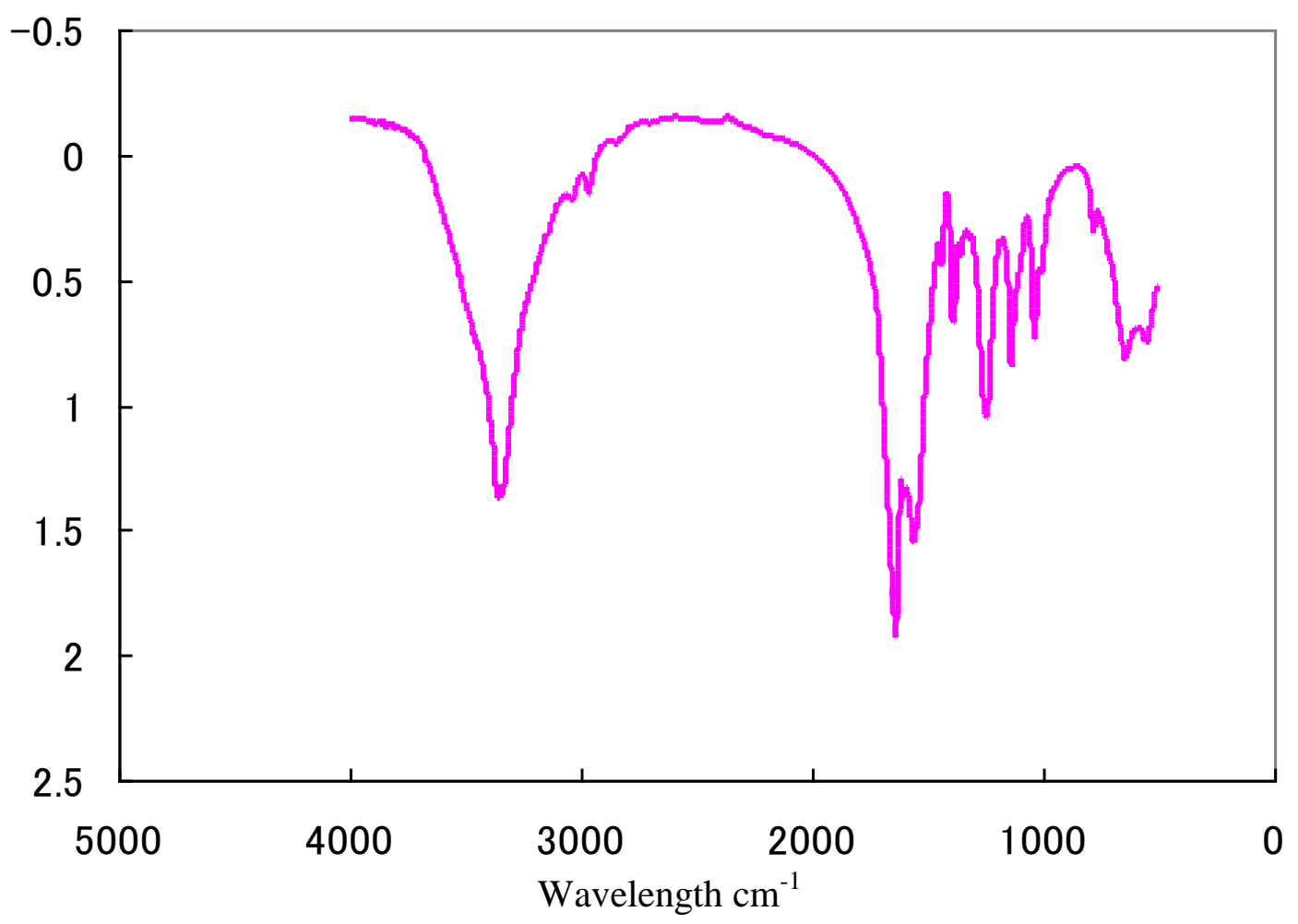

Figure 4 IR spectrum of precipitates from synthetic urine 


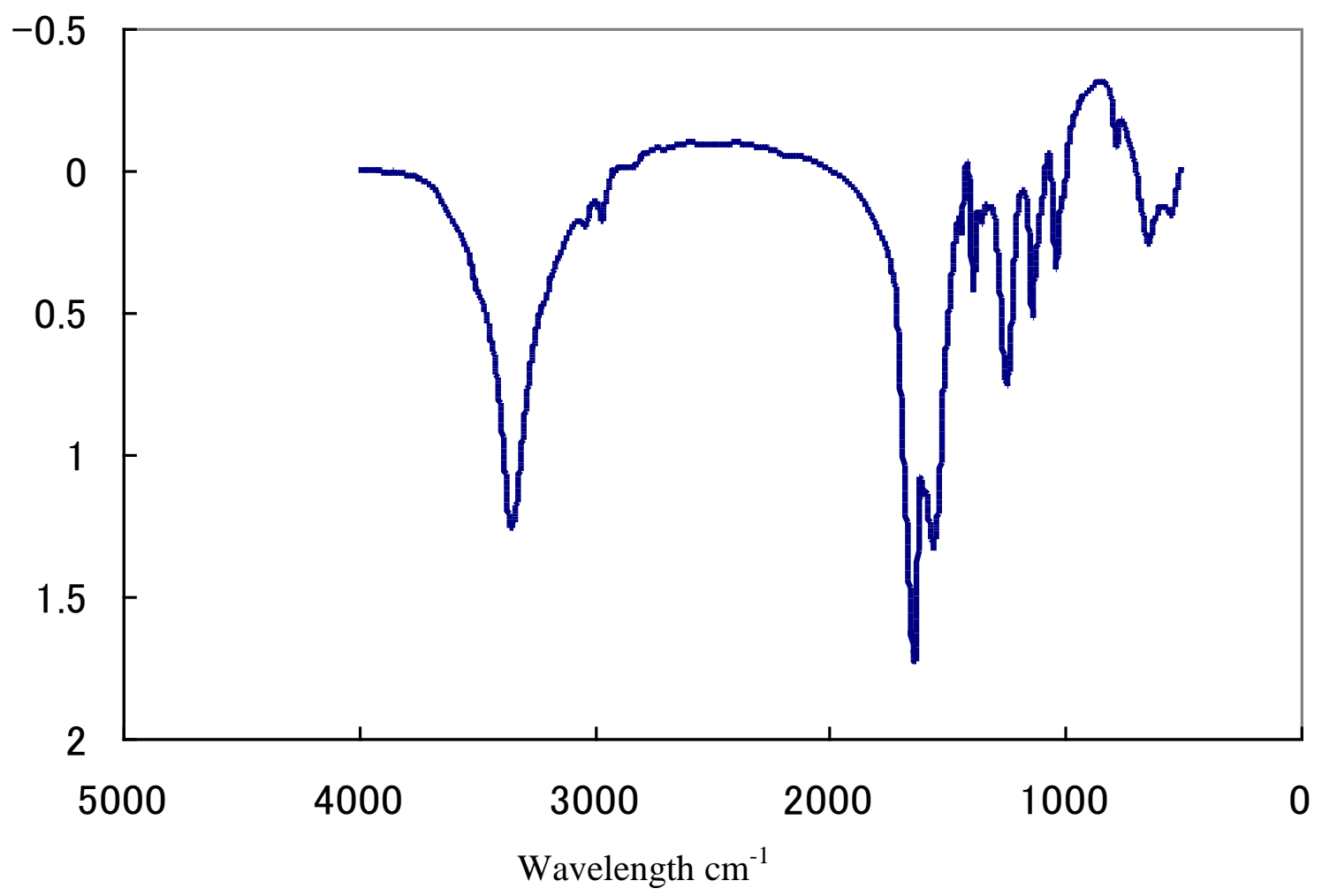

Figure 5 IR spectrum of precipitates from urea solution 


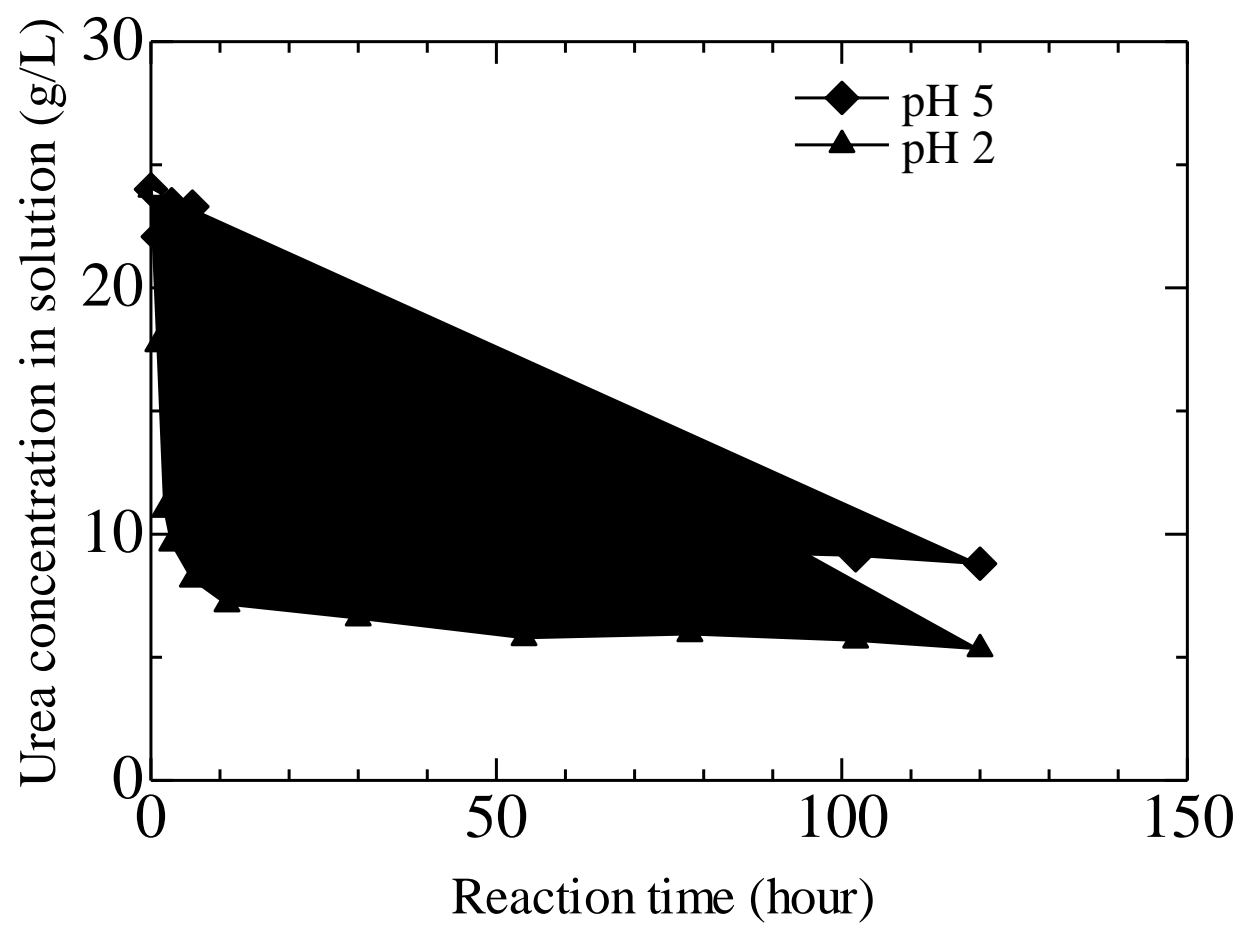

Figure 6 Urea concentration of normal synthetic urine 


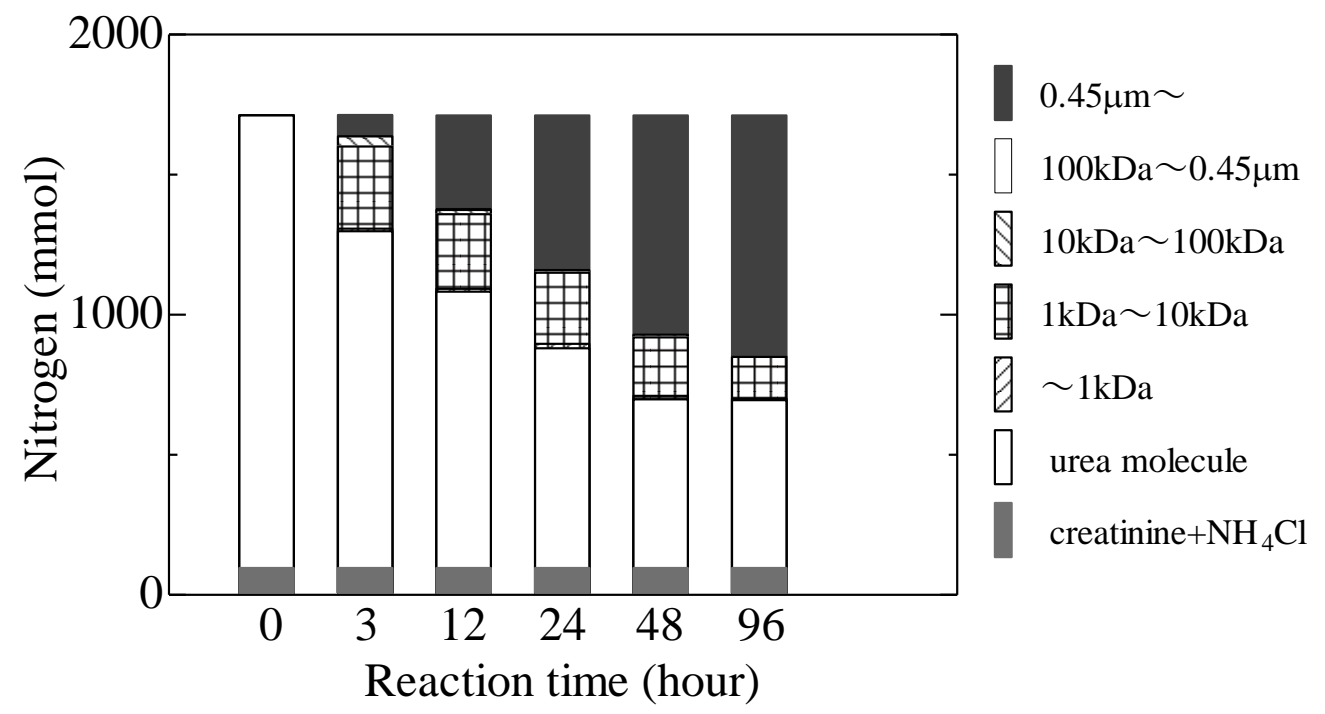

Figure 7 Molecular distribution of urea derivatives at $\mathrm{pH} 5$ 


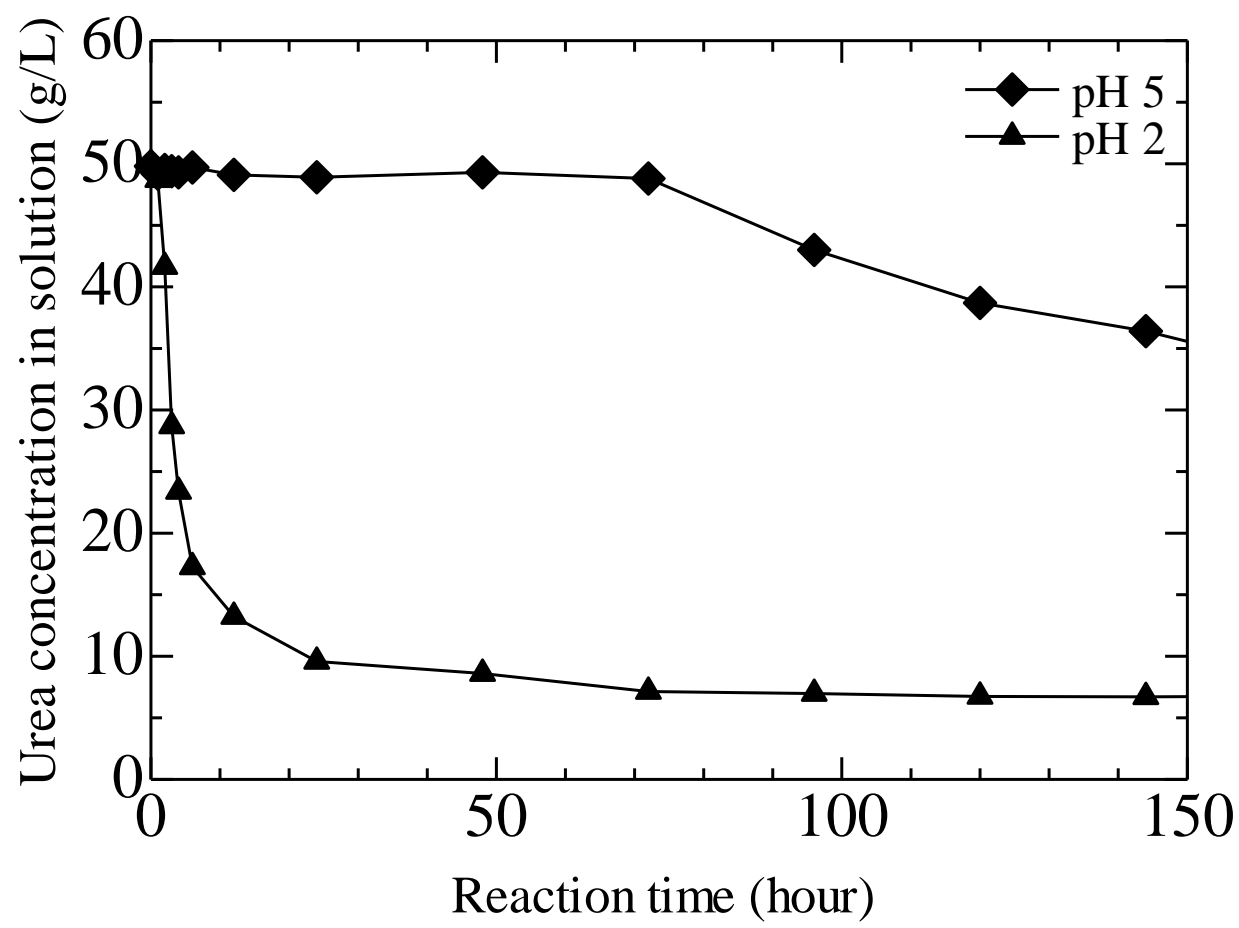

Figure 8 time courses of the urea concentration in the urea buffer solution 


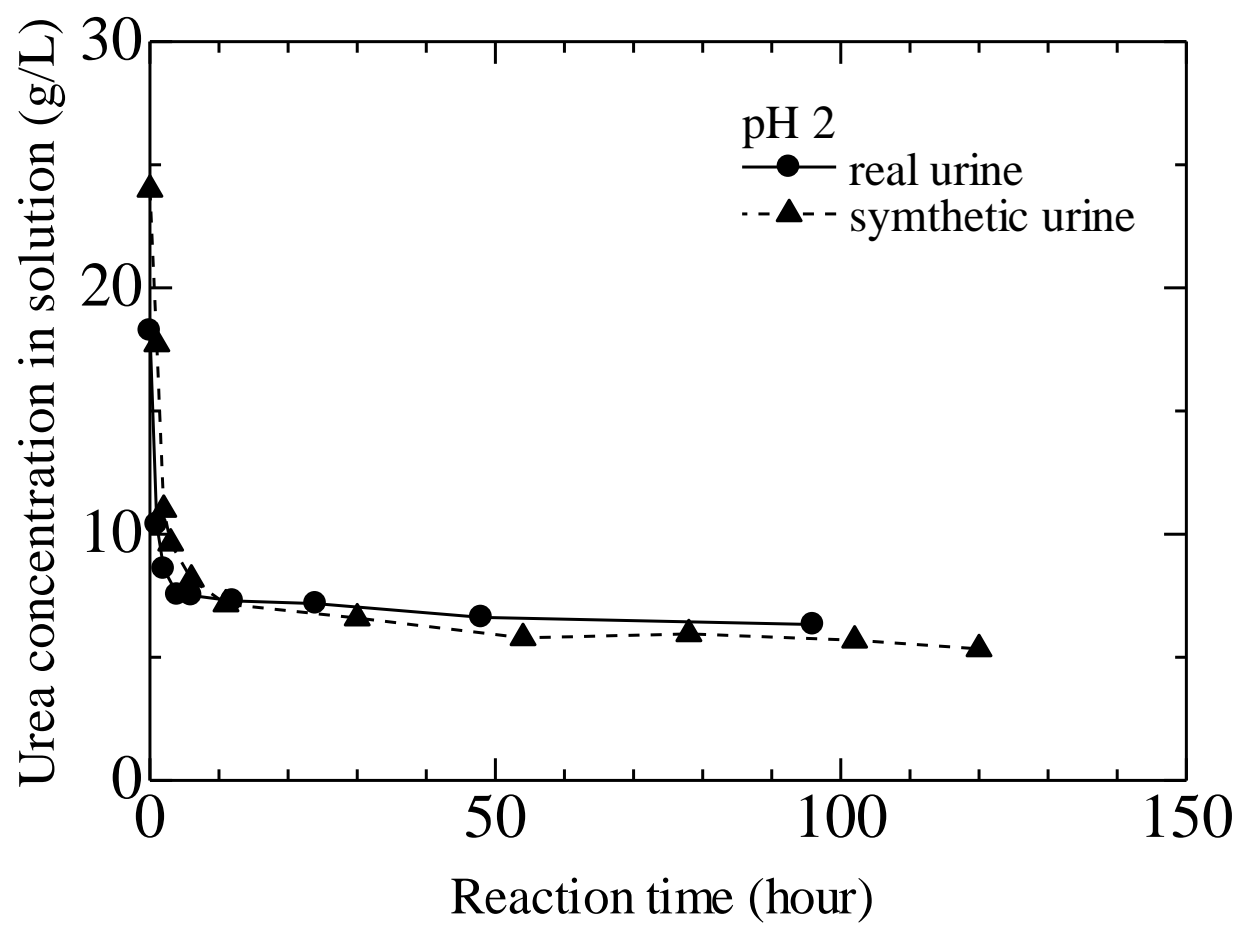

Figure 9 Urea concentration of real urine 


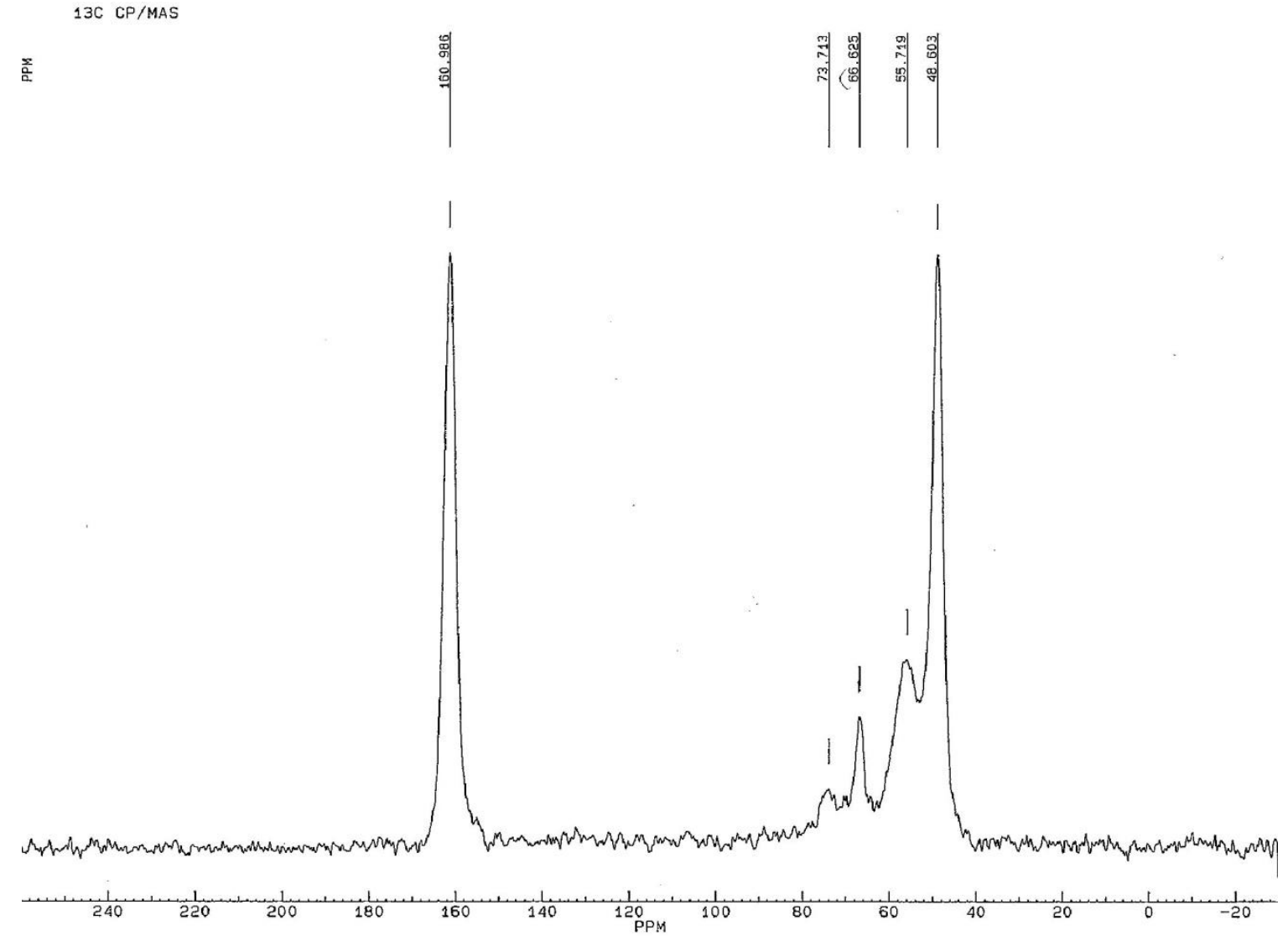

Figure 10 NMR spectrum of precipitates from synthetic urine 


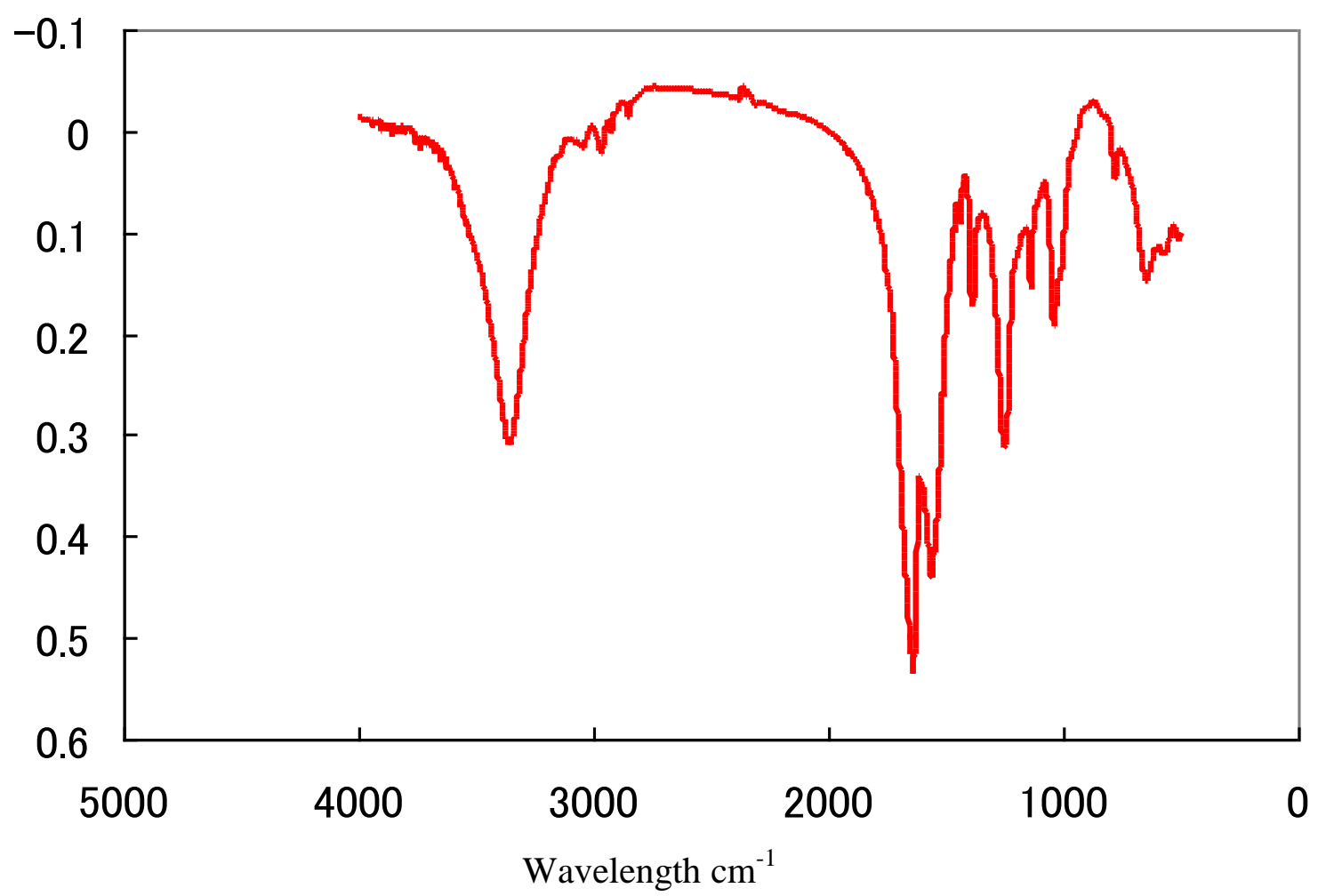

Figure 11 IR spectrum of precipitates from real urine 
Table 1 components of synthetic urine

\begin{tabular}{cc}
\hline Chemicals & Concentration (mmol/L) \\
\hline $\mathrm{MgCl}_{2} \cdot 6 \mathrm{H}_{2} \mathrm{O}$ & 3.2 \\
\hline $\mathrm{NaCl}$ & 78.7 \\
\hline $\mathrm{Na}_{2} \mathrm{SO}_{4}$ & 16.2 \\
\hline $\mathrm{Na}_{3}\left(\mathrm{C}_{6} \mathrm{H}_{5} \mathrm{O}_{7}\right) \cdot 2 \mathrm{H}_{2} \mathrm{O}$ & 2.6 \\
\hline $\mathrm{KCl}_{4}$ & 21.5 \\
\hline $\mathrm{C}_{4} \mathrm{H}_{7} \mathrm{~N}_{3} \mathrm{O}$ & 9.7 \\
\hline $\mathrm{CaCl}_{2} \cdot 2 \mathrm{H}_{2} \mathrm{O}$ & 4.4 \\
\hline $\mathrm{KH}_{2} \mathrm{PO}_{4}$ & 30.9 \\
\hline $\mathrm{NH}_{4} \mathrm{Cl}$ & 18.7 \\
\hline$\left(\mathrm{NH}_{2}\right)_{2} \mathrm{CO}$ & 417 \\
\hline $\mathrm{Na}_{2}\left(\mathrm{COO}_{2}\right.$ & 0.15 \\
\hline $\mathrm{C}_{6} \mathrm{H}_{8} \mathrm{O}_{6}$ & 0.57 \\
\hline
\end{tabular}

